\title{
Associations of Race with Follow-up Patterns After Initial Abnormal Liver Tests in Primary Care
}

\author{
John Bian, Ph.D., Andrew D. Schreiner, M.D., M.S.C.R., Jingwen Zhang, M.S., \\ Samuel O. Schumann, M.D., M.S.C.R., Don C. Rockey, M.D., Patrick D. Mauldin, Ph.D., and \\ William P. Moran, M.D., M.S.
}

Department of Medicine, Medical University of South Carolina, Charleston, SC, USA.

KEY WORDS: disparities; health services research; preventive care; primary care.

J Gen Intern Med 33(10): 1618-20

DOI: $10.1007 / \mathrm{s} 11606-018-4535-2$

(C) Society of General Internal Medicine 2018

\section{INTRODUCTION}

Black patients are at higher risk than white patients of having liver diseases such as viral hepatitis, cirrhosis, and hepatocellular carcinoma ${ }^{1}$. Abnormal liver tests occur frequently in the primary care setting, suggesting possible early or previously undiagnosed liver diseases. Current guidelines recommend repeating liver tests as an initial step in response to abnormalities ${ }^{2-4}$. As such, prompt follow-up of abnormal tests may offer the potential to diagnose and treat liver disease early, reducing the risk of progression to cirrhosis ${ }^{5,6}$. Little is known about the associations of race with follow-up patterns after initial abnormal liver tests. This was the first study that examined the black-white differences in follow-up testing after the initial abnormalities in primary care.

\section{METHODS}

This was a retrospective study of administrative data of primary care services provided at the Medical University of

Table 1 Mean Statistics (Proportion) of Patients at Index Abnormal Liver Testing

\begin{tabular}{|c|c|c|c|c|c|c|}
\hline \multirow{2}{*}{$\begin{array}{l}\text { Sample } \\
\\
\text { Race }\end{array}$} & \multicolumn{3}{|c|}{$\begin{array}{l}\text { Patients with index abnormal } \\
\text { liver tests }\end{array}$} & \multicolumn{3}{|c|}{$\begin{array}{l}\text { Patients with follow-up liver tests } \\
\text { ordered within } 90 \text { days post index } \\
\text { tests }\end{array}$} \\
\hline & Black & White & $P$-value & Black & White & $P$ value \\
\hline Sample size & $(897)$ & $(958)$ & & $(442)$ & $(417)$ & \\
\hline \multicolumn{7}{|l|}{ (Dependent variable) } \\
\hline Follow-up test ordered* & 0.493 & 0.435 & $<0.05$ & $\mathrm{~N} / \mathrm{A}$ & $\mathrm{N} / \mathrm{A}$ & \\
\hline Follow-up test completed $\dagger$ & $\mathrm{N} / \mathrm{A}$ & N/A & & 0.772 & 0.648 & $<0.0001$ \\
\hline \multicolumn{7}{|l|}{ (Independent variables) } \\
\hline Male & 0.324 & 0.386 & $<0.05$ & 0.310 & 0.350 & 0.21 \\
\hline Age & & & 0.33 & & & 0.22 \\
\hline Age $<50$ & 0.246 & 0.246 & & 0.249 & 0.249 & \\
\hline $50 \leq$ Age $<65$ & 0.351 & 0.322 & & 0.319 & 0.269 & \\
\hline Age $\geq 65$ & 0.403 & 0.432 & & 0.432 & 0.482 & \\
\hline Medicaid enrollment status & 0.190 & 0.067 & $<0.0001$ & 0.204 & 0.074 & $<0.0001$ \\
\hline \multicolumn{7}{|l|}{ Status of abnormality by type of liver test } \\
\hline BILI & 0.264 & 0.254 & 0.60 & 0.299 & 0.237 & $<0.05$ \\
\hline ALT & 0.346 & 0.410 & $<0.05$ & 0.385 & 0.484 & $<0.05$ \\
\hline AST & 0.657 & 0.603 & $<0.05$ & 0.708 & 0.686 & 0.48 \\
\hline ALK & 0.180 & 0.099 & $<0.0001$ & 0.213 & 0.139 & $<0.05$ \\
\hline Primary care physician attribution & & & $<0.0001$ & & & $<0.0001$ \\
\hline Faculty & 0.198 & 0.465 & & 0.179 & 0.439 & \\
\hline Non-university provider & 0.310 & 0.391 & & 0.326 & 0.391 & \\
\hline Resident & 0.492 & 0.144 & & 0.496 & 0.170 & \\
\hline Distance (miles) from patient residence to university & & & $<0.05$ & & & $<0.05$ \\
\hline Distance $<5$ & 0.314 & 0.304 & & 0.310 & 0.293 & \\
\hline $5 \leq$ Distance $<10$ & 0.293 & 0.230 & & 0.308 & 0.235 & \\
\hline $10 \leq$ Distance $<30$ & 0.269 & 0.340 & & 0.253 & 0.353 & \\
\hline Distance $\geq 30$ & 0.124 & 0.126 & & 0.129 & 0.120 & \\
\hline Year & & & 0.79 & & & 0.65 \\
\hline April 2012-M arch 2013 & 0.271 & 0.267 & & 0.285 & 0.247 & \\
\hline April 2013-March 2014 & 0.259 & 0.254 & & 0.262 & 0.271 & \\
\hline April 2014-March 2015 & 0.263 & 0.253 & & 0.249 & 0.261 & \\
\hline April 2015-March 2016 & 0.207 & 0.227 & & 0.204 & 0.221 & \\
\hline
\end{tabular}

*Status of follow-up liver tests ordered within 90 days post index testing

†Status of follow-up liver tests completed within 180 days post ordered follow-up testing

Published online June 22, 2018 


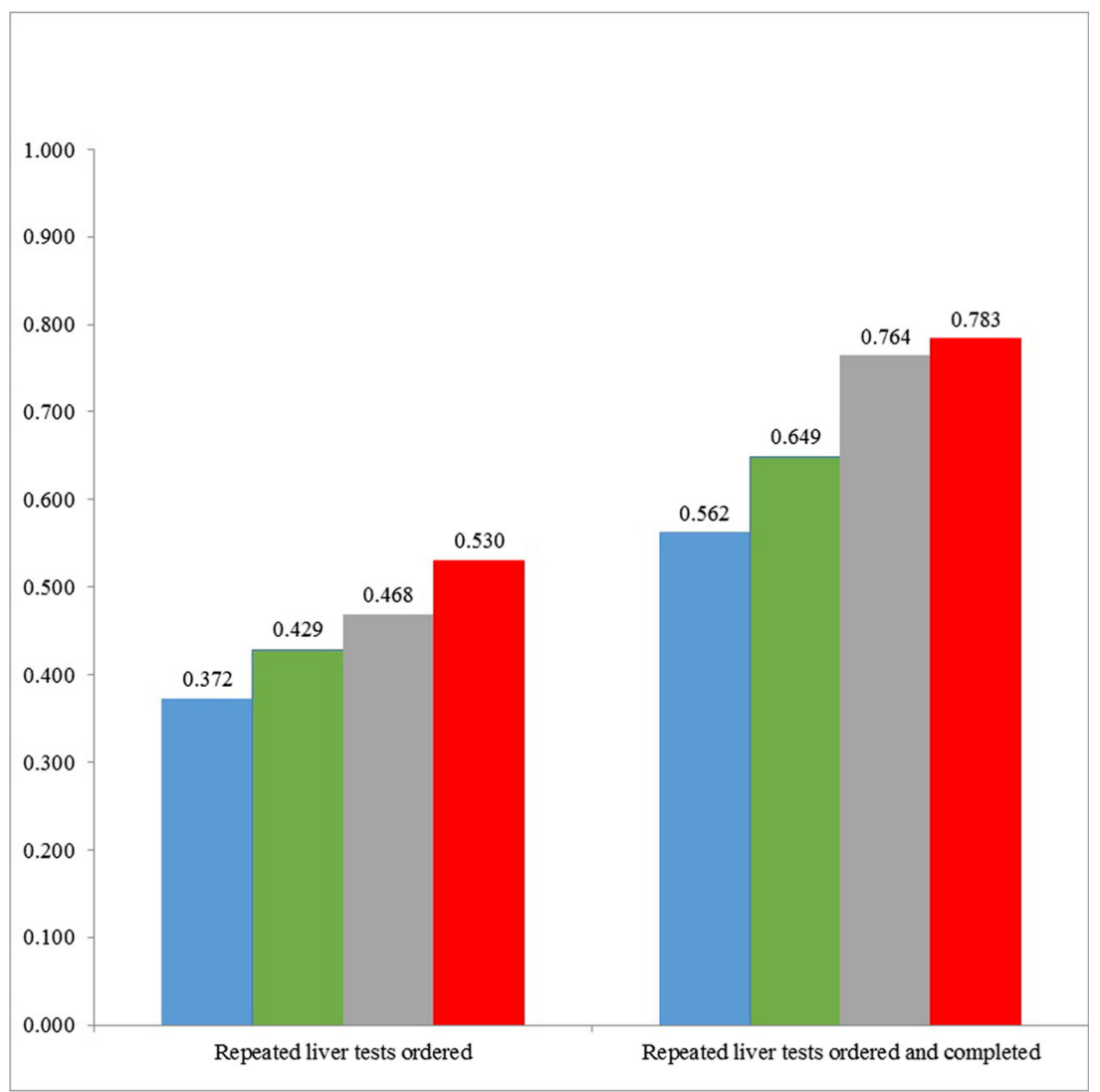

Fig. 1 Follow-up patterns (proportion) after index liver test abnormality by race and primary care physician attribution (faculty vs. resident). Blue, white patients seen by faculty; green, black patients seen by faculty; gray, black patients seen by resident; red, white patients seen by resident.

South Carolina from 2012 to 2016. We constructed a biracial sample of patients (either black or white) with at least one abnormal liver test result. Liver test abnormality was defined as having at least one abnormal test out of a set of four tests: abnormal bilirubin (BILI) $>1.2 \mathrm{MG} / \mathrm{DL}$, abnormal alanine aminotransferase (ALT) $>45 \mathrm{IU} / \mathrm{L}$, abnormal aspartate aminotransferase $(\mathrm{AST})>34 \mathrm{IU} / \mathrm{L}$, or abnormal alkaline phosphatase $(\mathrm{ALP})>150 \mathrm{IU} / \mathrm{L}$. The index abnormal liver test for a given patient was defined as the first recorded abnormality during the study period. We further excluded patients without at least one set of four normal tests prior to the index.

Two binary dependent variables were the status of the follow-up liver tests ordered within 90 days post the index abnormality, and the status of the follow-up liver tests completed within 180 days post the order of a repeated liver test. The key independent variable was a biracial indicator. Other demographic, socioeconomic, and primary care physician (PCP) attribution variables were also included. The main analysis applied multivariable logistic regression models, in which the unit of analysis was a unique patient, for examining the associations of race with follow-up.

\section{RESULTS}

Among the full sample of 1856 patients with abnormal liver tests during the study period, $49.3 \%$ of 897 black patients had an order for follow-up liver tests within 90 days after the index abnormality compared to $43.5 \%$ of 958 white patients (Table 1 ). In the subsample of 859 patients with an order for follow-up testing within 90 days after the index abnormality, $77.2 \%$ of 442 black patients completed the follow-up testing within 180 days of the order compared to $64.8 \%$ of 417 white patients.

We performed a descriptive analysis of the potential interactions of race and PCP attribution (Fig. 1). In the full sample, the difference in the proportion of white patients with a followup order between resident and faculty groups (15.8 percentage points) was four times that observed in black patients (3.9 percentage points). In the subsample, the difference in the proportion of white patients completing the test between resident and faculty groups (22.1 percentage points) was approximately twice as large as the difference (11.5 percentage points) among black patients.

Regression analysis of the full sample showed no association of race with the likelihood of an order for follow-up liver testing $(P=0.45)$. However, our subsample analysis showed that black patients were more likely than white patients to complete follow-up tests $(\mathrm{OR}=1.42, P<0.05)$.

\section{DISCUSSION}

Our study found no association of race with follow-up orders after an initial abnormal liver test. However, black patients were more likely to complete orders for follow-up testing in primary care within a single institution. (Of note, this 
associational study did not try to isolate the impact of race as the genetic determinant from the impact of race as socioeconomic and cultural determinants.)

Our study suggested patients with a resident PCP were more likely to have and complete an order for follow-up than those patients with a faculty PCP. Some combination of race and PCP attribution may play a role in ordering follow-up tests, an observation enduring to order completion. Potentially contributing factors include differences in relationships, communication, trust, the frequency of in-person visits, and understanding of care access barriers. This interaction of race and PCP attribution may warrant additional investigation into overuse or underuse of liver tests by physician experience.

Corresponding Author: John Bian, Ph.D.; Department of Medicine Medical University of South Carolina, Charleston, SC, USA (e-mail: bian@musc.edu).

Author's Contribution All authors listed here have made significant contributions to the study and manuscript.

\section{Compliance with Ethical Standards:}

Conflict of Interest: The authors declare that they do not have a conflict of interest.

\section{REFERENCES}

1. Guy J, Yee HF, Jr. Health disparities in liver disease: Time to take notice and take action. Hepatology (Baltimore, Md). 2009;50(1):309-313.

2. Kwo PY, Cohen SM, Lim JK. ACG Clinical Guideline: Evaluation of Abnormal Liver Chemistries. Am J Gastroenterol. 2017;112(1):18-35.

3. Newsome PN, Cramb R, Davison SM, et al. Guidelines on the management of abnormal liver blood tests. Gut. 2018;67(1):6-19.

4. Pratt DS, Kaplan MM. Evaluation of abnormal liver-enzyme results in asymptomatic patients. N Engl J Med. 2000;342(17):1266-1271.

5. Donnan PT, McLernon D, Dillon JF, et al. Development of a decision support tool for primary care management of patients with abnormal liver function tests without clinically apparent liver disease: a record-linkage population cohort study and decision analysis (ALFIE). Health technology assessment (Winchester, England). 2009;13(25):iii-iv, ix-xi, 1-134.

6. Reau N, Vekeman F, Wu E, Bao Y, Gonzalez YS. Prevalence and economic burden of extrahepatic manifestations of hepatitis C virus are underestimated but can be improved with therapy. Hepatol Commun. 2017;1(5):439-452. 